\title{
Effectiveness of active control of surface charge of filter media on separation of microparticles from contaminated wastewater
}

\author{
A. K. M. Ashadullah ${ }^{1} \cdot$ Naoyuki Kishimoto ${ }^{2}$
}

Received: 12 September 2016 / Accepted: 14 November 2018 / Published online: 21 November 2018

(c) The Author(s) 2018

\begin{abstract}
Depth filtration is a conventional concept for the solid-liquid separation process through granular media, and this technique is very useful in removal of large-sized particle. However, in the case of microparticles smaller than the pore space it does not function well. Accordingly, an effective small particle removal technique is desired. In this research, a carbon fiber felt was introduced as filter media and $\pm 1.0 \mathrm{~V}$ terminal voltage was applied for activating the media to enhance in adsorbing as well as desorbing the fine particles in the filtration and back-washing. Kaolin particles in the range of 0.1-4.0 $\mu \mathrm{m}$ were used as a model of microparticles. The complete kaolin particle removal was observed in pure water, and it decreased to around $50 \%$ in the anionic surfactant-contaminated wastewater at the hydraulic loading of $283 \mathrm{~L} / \mathrm{m}^{2} / \mathrm{min}$. On the contrary, at the back-washing hydraulic loading of $1274 \mathrm{~L} / \mathrm{m}^{2} / \mathrm{min}$, the kaolin particle washout removal efficiency was found to be around $73 \%$ in pure water and it dramatically decreased and found within the range of 5-50\% when the kaolin was in contact with anionic surfactant and wastewater. Although the kaolin particle washout removal rate was observed very low in wastewater, this technique would be very useful in enhancing the refreshment of the filter media for extending the production time of the filter.
\end{abstract}

Keywords Carbon fiber felt $\cdot$ Depth filtration $\cdot$ Kaolin $\cdot$ Microparticle $\cdot$ Terminal voltage

\section{Introduction}

Over the last half century, depth filtration process in porous bed has become more common in wastewater treatment area due to the stringent effluent quality standards (Torkzaban et al. 2010). In this method, solid particles in suspension are generally adsorbed on or retained by the media while filtration. However, the effectiveness of particles removal depends on the surface forces acting between particles and filter grains. The latter is significant when distance between particles and filter grains is in the order of nanometers (Aiken et al. 2011).

\section{A. K. M. Ashadullah}

akmashadullah@gmail.com

1 Department of Environmental Solution Technology, Graduate School of Science and Technology, Ryukoku University, 1-5 Yokotani, Seta Oe-cho, Otsu-shi, Shiga 520-2194, Japan

2 Department of Environmental Solution Technology, Faculty of Science and Technology, Ryukoku University, 1-5 Yokotani, Seta Oe-cho, Otsu-shi, Shiga 520-2194, Japan
Numerous complementary research works have been performed to clearly understand the effects of media material on removal of SS by depth filtration (Sun et al. 2015). Still in recent years, depth filtration models cannot completely account for the fundamental insights concurring with a large variety of solid loading rate for wastewater filtration (Ding et al. 2015). It is well known that tiny particles separation is a very complex process and influenced by several factors such as wastewater characteristics, types of SS, and the operation mode of filtration (Bedrikovetsky et al. 2011). When filtration proceeds over time without back-washing, effluent quality may be improved but clogging of filter bed will result in an increase in head loss and a decrease in filtration flux (Loderer et al. 2012). Clogging and head loss are influenced by various factors such as particle size distribution, particle concentration, particle surface chemistry, filter media size, and media type (Coustumer et al. 2012). Filter media with an uneven media size distribution normally have a greater chance of clogging than uniform filter media. The formation of clogging depends on the size distribution of SS, fine bedload, and channel sediments. Large fine particles diameter more than $30 \mu \mathrm{m}$ are subjected to mechanical filtration rather 
than surface phenomena such as the van deer Waals force. Medium-sized particles between 3 and $30 \mu \mathrm{m}$ are retained by both filtration mechanisms. Adhesion of colloidal particles and bacteria is exclusively due to physiochemical process (Wang et al. 2012).

In general, performance of a filter is quantified by particle removal efficiency and head loss across the packed bed. Since filtration is often thought to be a unit operation at posttreatment stage in wastewater treatment process, a secure removal of SS is required to satisfy the specific standard limit. In depth filtration mechanism, large and submicron particles, colloidal, and insoluble materials are removed while passing through a tortuous path before it is able to reach the other side (Karan et al. 2013). Figure 1 shows the flow of fluid and particles through depth filter media.

It is logical that particles larger than the pore size would be easily removed by mechanical filtration that is termed as sieving, straining, or size exclusion. In addition, adsorption and attraction mechanisms are also observed in depth filtration, where particles are adsorbed by the electrokinetic force or surface affinity. Relatively large particles impact the filter medium through inertia, and relatively small particles impact through random Brownian motion. In these processes, particles are finally adsorbed on the filter medium by the van der Waals force or the interaction in the electric double layers (EDLs) of the surfaces (Mahmoud et al. 2010). However, the removal of particles smaller than the pore size and microorganisms like total coliform (TC) and general bacteria (GB) is less intuitive. In this case, an electrokinetic effect in charge-modified depth filter media would be able to remove these submicron particles, colloidal materials, and insoluble contaminants (Loo et al. 2012). Natural particles and colloids in water usually have a negative surface charge. Therefore, if filter media have an opposite surface charge against particles in water, the particle removal performances of the system will be enhanced (Keller et al. 2010; Ghernaout and Ghernaout 2012).

Considering this notion, a laboratory-scale depth filtration system was developed using a conducting carbon fiber felt made from polyacrylonitrile fibers with $5.3 \mu \mathrm{m}$ in diameter as filter media, in which surface charge of filter media was actively controlled with a direct current (DC) power supply. In this system, wastewater filtration was performed under a positive surface charge of the filter media and back-washing was performed under a negative surface charge. These operations would enhance the particle rejection and backwashing effect through electrostatic interactions between particles and media surface (Kishimoto et al. 2010). The specific objectives of this research were to find out an optimum condition of the active surface charge control depth filter for the removal of fouling materials of the RO membrane such as organic and inorganic particles. In addition, efficacy of this system on desorption of particles from filter media at the back-washing step was also explored.

\section{Materials and methods}

\section{Experimental setup}

Figure 2 shows the experimental setup. The laboratory-scale experimental system was composed of a filter module, a feed pump (RP-1000, EYELA, Japan), a digital DC power supply (AD-8735D, AND, Japan), and a high-power ultrasonic cleaner (SUS-200, Shimadzu, Tokyo, Japan).

The filter module was constituted of a filter bed chamber made of silicon rubber with $2.5 \mathrm{~cm}$ height and two covers made of acrylic resin with an inlet or outlet. Five sheets of carbon fiber felt (weight per area: $250 \mathrm{~g} / \mathrm{m}^{2}$; Kanai Juyo Kogyo, Osaka, Japan) with $3 \mathrm{~cm}$ in diameter and $0.5 \mathrm{~cm}$ in thickness were stacked in the filter module. Two porous stainless steel (ANSI304) plates with $5 \mathrm{~mm}$ pores were set at the upper and lower end of the filter module as a counter electrode and a conductor to the carbon fiber felt, respectively. A polytetrafluoroethylene mesh sheet with $1 \mathrm{~mm}$ in thickness was inserted between upper stainless steel plate sheet and carbon fiber felt as a separator. The empty volume of filter bed chamber was $17.7 \mathrm{~cm}^{3}$.
Fig. 1 Flow of fluid and particles through depth filter media

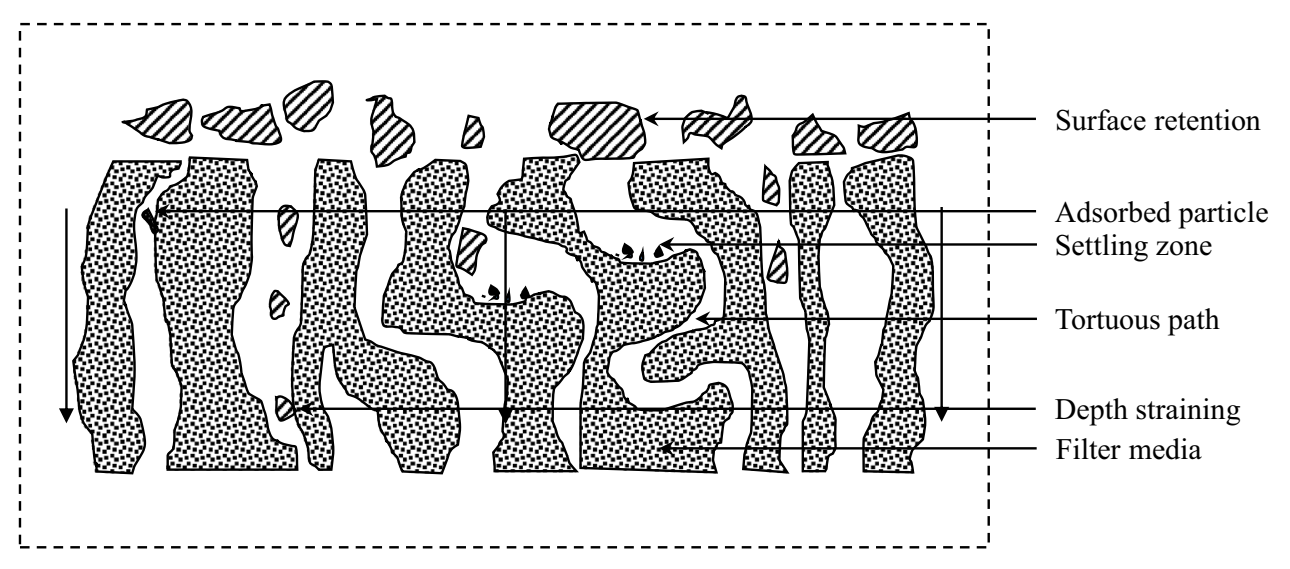



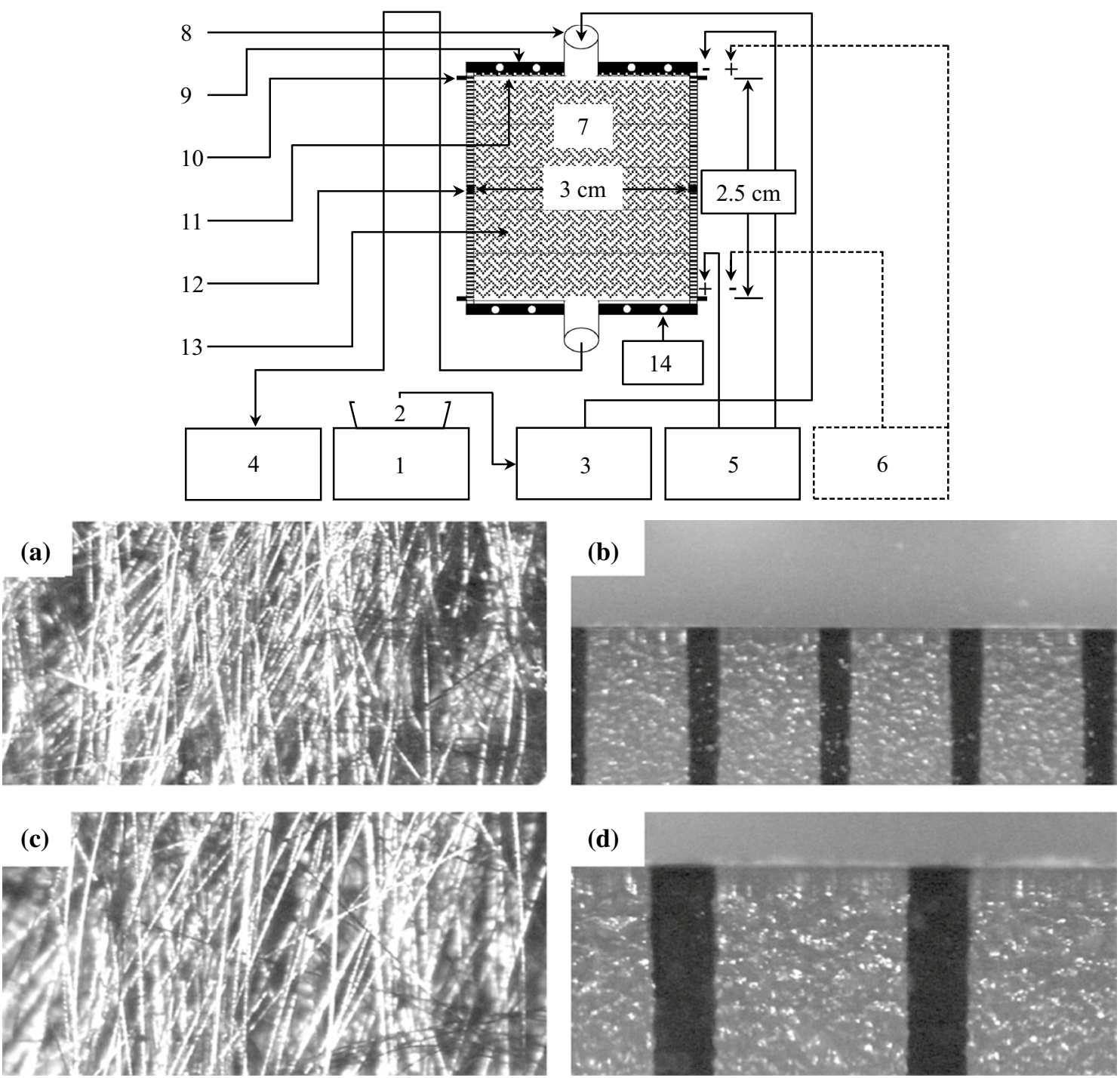

(d)

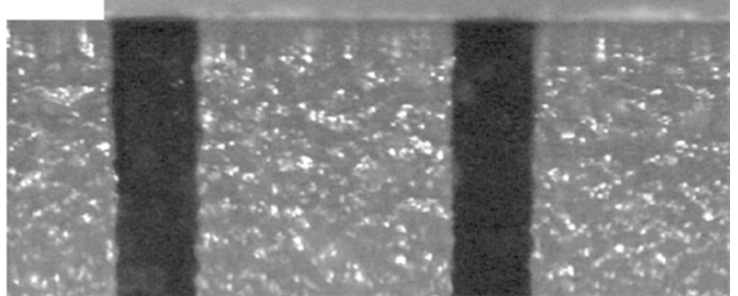

Fig. 2 Laboratory-scale experimental setup. 1: ultrasonic cleaner, 2: influent, 3: feed water pump, 4: effluent, 5: DC power supply in filtration mode, 6: DC power supply in back-washing mode, 7: filter module, 8: acrylic tube, 9: acrylic resin cover, 10: porous stainless steel plate, 11: polytetrafluoroethylene mesh, 12: silicon rubber, 13: carbon fiber felt, and 14: bolts. a Picture of the carbon fiber felt with

\section{Experimental procedure and operational conditions}

Before each experimental run, the filter module was washed with deionized water (DW) of electrical conductivity (EC) less than $1 \mu \mathrm{S} / \mathrm{cm}$, unless and until particles were not detected in the effluent. In this study, Run 1 was conducted to observe the kaolin particle removal efficiency in DW with no electric charge to the filter bed, Run 2 was conducted to observe the effect of conductivity on kaolin particle removal performances with no electric charge, and Run 3 was conducted to observe the effect of electric charge to the filter bed on kaolin particle removal performances.

the magnitude of 75 times, b picture of scale with the $1000 \mu \mathrm{m} / \mathrm{scale}$ (magnitude of 75 times), c picture of the carbon fiber felt with the magnitude of 150 times, $\mathbf{d}$ picture of scale with the $1000 \mu \mathrm{m} / \mathrm{scale}$ (magnitude of 150 times). These pictures were taken with a digital microscope (VH-5000, Keyence, Osaka, Japan)

The kaolin particle removal efficiency in synthetic contaminated source water was observed in Runs 4 and 5 at $\mathrm{pH}$ 6.7 and 7.8 , respectively. Runs 4 and 5 demonstrated the effect of synthetic contaminated source water $\mathrm{pH}$ on kaolin particle removal performances at around neutral $\mathrm{pH}$. Run 6 was demonstrated to observe the effect of anionic surfactant on kaolin particle removal performances. The Fe and kaolin particle removal performances were observed in Runs 7 and 8 at $\mathrm{pH} 4.6$ and 8.6, respectively. Runs 7 and 8 demonstrated the effect of acidic and alkaline $\mathrm{pH}$ on kaolin particle and $\mathrm{Fe}$ colloids removal performances. Moreover, the effect of anionic surfactant in $\mathrm{Fe}$ and kaolin particle removal performances was observed in Runs 9 and 10 at $\mathrm{pH} 3.8$ and 7.9,

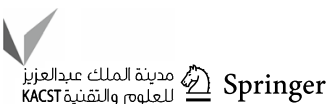


Table 1 Operational conditions of Runs 1-10

Empty volume of the filter module $=17.7 \mathrm{~cm}^{3}$

Applied voltage in Runs 1-2= Not applied

Applied voltage in Runs 3-10=+1.0 V

Filtration hydraulic loading of Runs $1-10=283 \mathrm{~L} / \mathrm{m}^{2} / \mathrm{min}$

Filtrated water volume of Runs $1-10=800 \mathrm{~mL}$

Back-washing hydraulic loading of Runs $1-10=1274 \mathrm{~L} / \mathrm{m}^{2} / \mathrm{min}$

Back-washed water volume of Runs $1-10=1000 \mathrm{~mL}$

respectively. Runs 9 and 10 were demonstrated to observe the effect of anionic surfactant on kaolin and Fe colloids removal performances at acidic and alkaline $\mathrm{pH}$. Here, the objectives of doing several runs were to find out the exact parameters that influence on the kaolin particle and Fe colloids removal performances.

Tables 1 and 2 show the operational conditions and the synthetic influent characteristics of Runs 1-10, respectively. The potential of the conducting carbon felt against the counter electrode in the filter module was set to $\pm 1.0 \mathrm{~V}$ at filtration mode of Runs 3-10, though the potential was not applied at Runs 1-2 (Table 1). At the back-washing mode, the potential was reversely changed to $-1.0 \mathrm{~V}$ at Runs $3-10$ and the potential was not applied at Runs $1-2$. The terminal voltage was set $\pm 1.0 \mathrm{~V}$, because this terminal voltage was within the potential window of water electrolysis, where electricity was used only for charging of the EDLs of filter media and the counter electrode (Loo et al. 2012). The back-washing solutions were flowed from the opposite direction of filtration mode at all experimental runs as shown in Fig. 2 to remove the clogged or retained particles in the filter media, which is defined as washout step. The filtration hydraulic loading and filtrated water volume of Runs $1-10$ was $283 \mathrm{~L} / \mathrm{m}^{2} / \mathrm{min}$ and $800 \mathrm{~mL}$, respectively. On the other hand, the back-washing hydraulic loading and backwashed water volume of Runs $1-10$ was $1274 \mathrm{~L} / \mathrm{m}^{2} / \mathrm{min}$ and $1000 \mathrm{~mL}$, respectively.

Table 3 shows the synthetic contaminated source water characteristics of Runs 4 and 5. Here, the influent used in Runs 4-5 was municipal wastewater of Ryukoku University diluted by five times with normal tap water. After that, it was kept in room temperature for about 2 months. As a result, organic matter was decomposed into inorganic carbon, nitrate $\left(\mathrm{NO}_{3}{ }^{-}\right)$, and ammonium $\left(\mathrm{NH}_{4}{ }^{+}\right)$. Consequently, $\mathrm{NO}_{3}{ }^{-}$and $\mathrm{NH}_{4}{ }^{+}$concentrations were found to be higher than biochemical oxygen demand (BOD) and chemical oxygen demand (COD) (Table 3). The synthetic contaminated source water was filtrated using a glass fiber filter with 1- $\mu \mathrm{m}$ particle rejection (GF/B, Whatman, Japan) just before experimental runs.

In the back-washing experiments, DW was used as back-washing solution in Runs 1-2 and a sodium

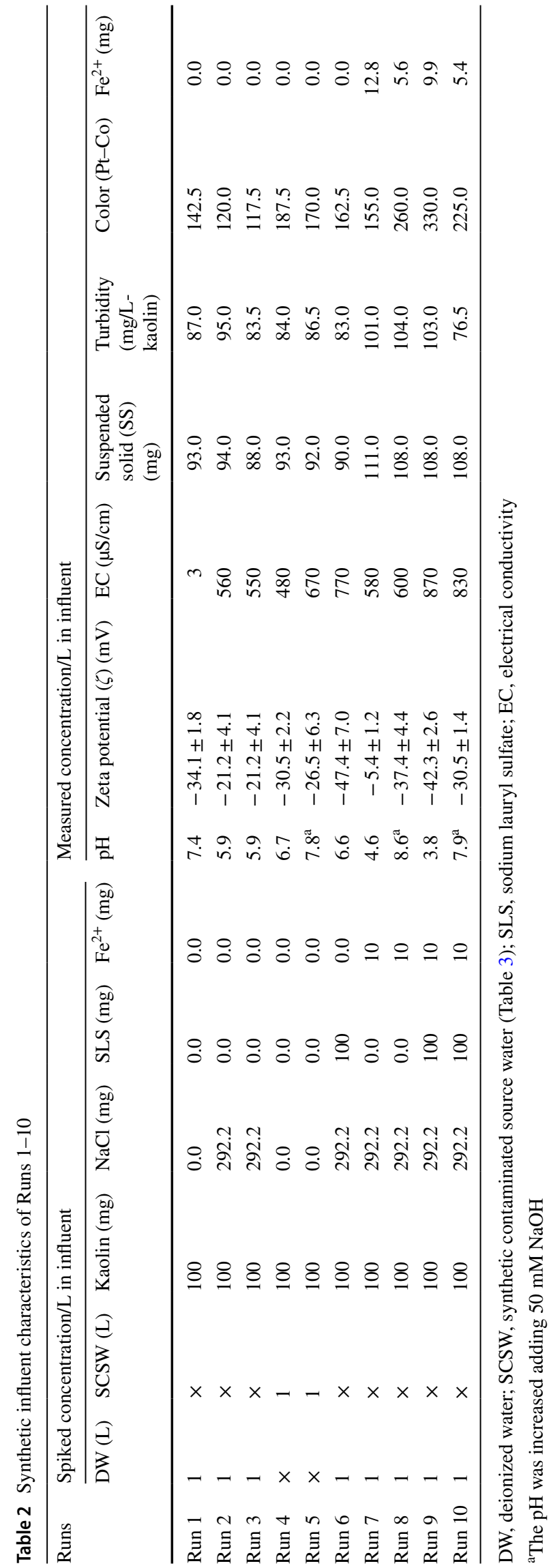


chloride $(\mathrm{NaCl})$ solution with $\mathrm{NaCl}$ concentration of $5 \mathrm{mM}$ (292.2 $\mathrm{mg} / \mathrm{L})(\mathrm{EC}=580 \mu \mathrm{S} / \mathrm{cm})$ was used in Runs 3-10. In the preparation of the influent of Runs 1-10 a high-power ultrasonic cleaner was operated for $30 \mathrm{~min}$ to promote the dispersion of fine particles. The ultrasonic cleaner was continuously operated during the filtration operation too. In this experimental study, kaolin powder of $0.1-4.0 \mu \mathrm{m}$ in diameter (Nacalai, Tesque, Kyoto, Japan), $\mathrm{NaCl}$, sodium lauryl sulfate $\left(\mathrm{CH}_{3}\left(\mathrm{CH}_{2}\right)_{11} \mathrm{OSO}_{3} \mathrm{Na}\right)$, and ferrous sulfate heptahydrate $\left(\mathrm{FeSO}_{4} \cdot 7 \mathrm{H}_{2} \mathrm{O}\right)$ were used for the source of microparticles, electron conductor, anionic surfactant, and ferrous ion, respectively. Moreover, $50 \mathrm{mM}(200 \mathrm{mg} / \mathrm{L})$ sodium hydroxide $(\mathrm{NaOH})$ was used as alkaline solution to increase the $\mathrm{pH}$ in Runs 5, 8, and 10, respectively.

\section{Analytical methods}

The $\mathrm{pH}$, dissolved oxygen (DO), and EC were measured with a pH meter (B-212, Horiba, Japan), a DO meter (LDO, HQ10, Hach, USA), and an EC meter (Twin Cond B-173, Horiba, Japan), respectively. A pH controller (FD02, Series-B, Japan) was used to adjust the pH. Turbidity and color were measured with a digital turbidity/color meter (Aqua Doctor, WA-PT-4DG, Kyoritsu ChemicalCheck Lab, Japan). Concentrations of nitrite $\left(\mathrm{NO}_{2}{ }^{-}\right)$, $\mathrm{NO}_{3}{ }^{-}$, and $\mathrm{NH}_{4}{ }^{+}$were determined by colorimetric method (4500- $\left.\mathrm{NO}_{2}{ }^{-} \mathrm{B}\right)$ (Rice et al. 2012), cadmium reduction method (4500- $\mathrm{NO}_{3}{ }^{-} \mathrm{E}$ ) (Rice et al. 2012), and phenate method (4500- $\mathrm{NH}_{3}$ F) (Rice et al. 2012), respectively. Ferrous ion $\left(\mathrm{Fe}^{2+}\right)$ was measured by phenanthroline method (3500-Fe B) (Rice et al. 2012). The BOD was measured by 5-day BOD test (5210 B) (Rice et al. 2012), and COD was measured by closed reflux colorimetric method (5220 D) (Rice et al. 2012). Particle size distributions of kaolin suspension and Fe colloids in influent, effluent, and backwashed water were measured with a laser diffraction particle size analyzer (SALD-300V, Shimadzu, Kyoto, Japan). Zeta potential was measured with a zeta potential meter (ZEECOM ZC-2000, Microtec, Funabashi, Japan). Total coliform (TC) and general bacteria (GB) were measured by test papers for TC and GB (Sibata, Saitama, Japan) using colony count, most-probable-number (MPN) method with thermostat incubator (CALBOX, CB-101, Sibata, Saitama, Japan). Filtrate was collected as effluent, and the mass of kaolin in the filtrate was measured as SS using glass fiber filter with $0.7-\mu \mathrm{m}$ particle rejection $(\mathrm{GF} / \mathrm{F}$, Whatman, Japan). DW with the EC less than $1 \mu \mathrm{S} / \mathrm{cm}$ was used for the dilution and preparation of standard solution, as obtained from a water purification system (Autostill, WA5000, Yamato, Japan). 


\section{Results and discussion}

\section{Zeta potential of particles}

Figure 3 shows the zeta potentials of particles at Runs 1-10 depending on $\mathrm{pH}$ and artificially spiked ingredients, namely kaolin particles, $\mathrm{NaCl}$, sodium lauryl sulfate, and $\mathrm{FeSO}_{4} \cdot 7 \mathrm{H}_{2} \mathrm{O}$ in the influent (Table 2). Here, the zeta potential of kaolin particles was found to be $-34.1 \mathrm{mV}$ in DW at pH 7.4 (Run 1). But, when $\mathrm{NaCl}$ was added to the suspension (Runs 2 and 3), $\mathrm{pH}$ decreased to 5.9 and zeta potential increased to $-21.2 \mathrm{mV}$, which would be caused by protonation with the decrease in $\mathrm{pH}$ (Leroy et al. 2011; Kishimoto et al. 2010; Aksoy and Kaya 2011).

However, the zeta potential of kaolin suspension in synthetic contaminated source water in Run 4 and 5 was found to be -30.5 and $-26.5 \mathrm{mV}$ at $\mathrm{pH} 6.7$ and 7.8 , respectively. In this case, $\mathrm{pH}$ was increased by the addition of $\mathrm{NaOH}$ in Run 5. Therefore, the zeta potential of kaolin particle in synthetic contaminated source water showed reverse behavior with $\mathrm{pH}$ due to the effect of positively charged sodium ion $\left(\mathrm{Na}^{+}\right)$in the kaolin suspension, which accords with the experimental results of Moayedi et al. (2011).

The zeta potential of Run 6 was found to be $-47.4 \mathrm{mV}$, which was lower than that of other runs, where kaolin particle and sodium lauryl sulfate were diluted with DW at $\mathrm{pH}$ 6.6. Since sodium lauryl sulfate is a negatively charged anionic surfactant, the adsorption of sodium lauryl sulfate onto the kaolin particle may take part in decreasing the zeta potential regardless of $\mathrm{pH}$ in the solution.

In the case of Runs 7 and 8, the zeta potentials of kaolin suspension in DW with $\mathrm{Fe}$ ions were found to be -5.4 and $-37.4 \mathrm{mV}$ at $\mathrm{pH} 4.6$ and 8.6, respectively. Since the zeta potential of ferric hydroxide $\left(\left(\mathrm{Fe}(\mathrm{OH})_{3}\right)\right.$ is reported to be positive at $\mathrm{pH}$ less than around 6 ( $\mathrm{Li}$ et al. 2010). The zeta potential in Run 7 was found to be higher than that of all runs, though the value was still negative. On the contrary, when the pH of Run 7 was increased to 8.6 (Run 8), the zeta potential decreased to $-37.4 \mathrm{mV}$ due to deprotonation effect (Aksoy and Kaya 2011).

The zeta potentials of Runs 9 and 10 were found to be -42.3 and $-30.5 \mathrm{mV}$ at $\mathrm{pH} 3.8$ and 7.9, respectively. Here, kaolin particle, sodium lauryl sulfate, and $\mathrm{FeSO}_{4} \cdot 7 \mathrm{H}_{2} \mathrm{O}$ were diluted in DW. The zeta potential in Run 9 was found to be lower than in Run 10. In the case of Run 9, negatively charged head of sodium lauryl sulfate (SLS) was associated with positively charged Fe colloids in Run 9. As a result, $\mathrm{Fe}$ colloids covered by SLS that hydrophobic tails are exposed to the outer side namely, bulk water. Then, other SLSs were associated with SLSs adsorbed on the Fe colloids by hydrophobic interaction. Consequently, the surface of the $\mathrm{Fe}$ colloid was covered by negatively charged heads of SLSs, which result in the low zeta potential. In Run 10, negatively charged surface of Fe colloids prevents the adsorption of SLS onto the Fe colloids. Accordingly, the zeta potential observed in Run 10 was higher than that in Run 9.

At a glance, the zeta potential characteristics of kaolin particles in pure water, synthetic contaminated source water, anionic surfactant, and Fe-contaminated water are summarized here. The zeta potential of kaolin particles and kaolin particles with $\mathrm{Fe}(\mathrm{OH})_{3}$ in pure water was found to increase with the decrease in $\mathrm{pH}$ probably due to the protonation effect (Runs 1, 2, 3, 7, and 8). However, the increment in zeta potential with the increment in $\mathrm{pH}$ was observed in Runs 4 and 5, where synthetic contaminated source water was added. Adsorption of positive ions/or organic ions in synthetic contaminated source water onto the kaolin surface

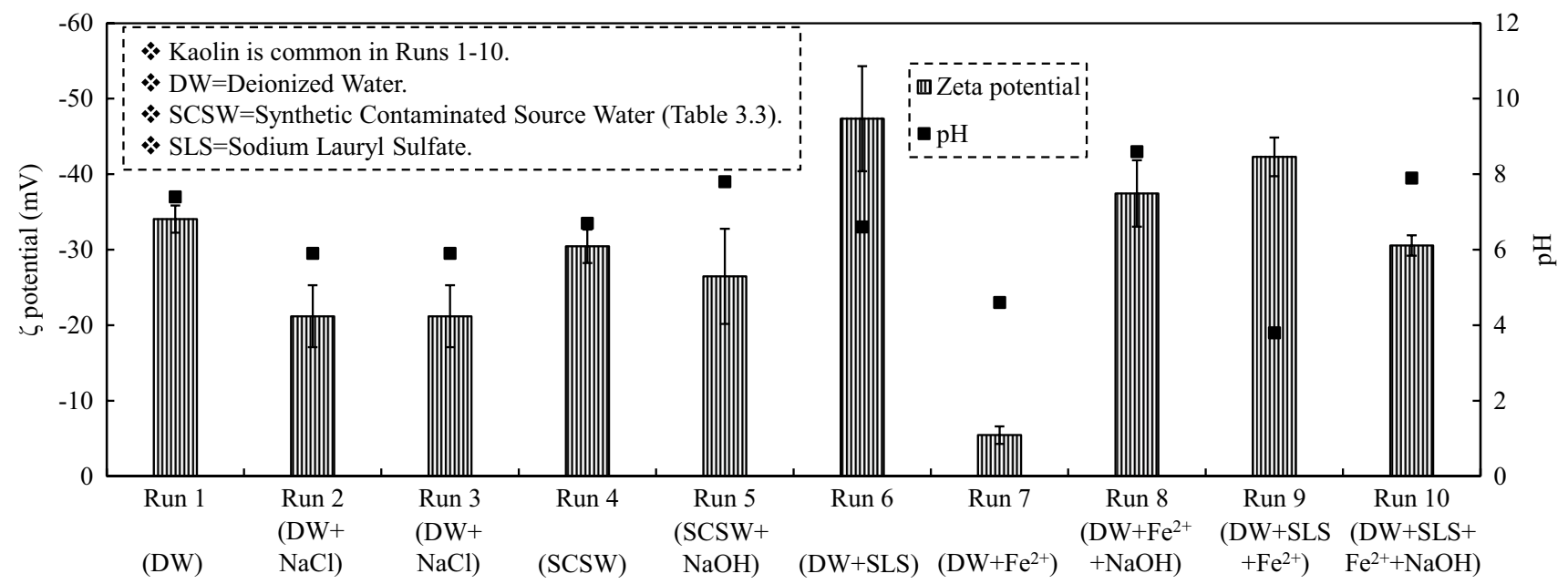

Fig. 3 Zeta potential characteristics of Runs 1-10, where kaolin was used as a model of common microparticles in Runs 1-10, sodium lauryl sulfate was used in Runs 6, 9, and 10, and Fe was used in Runs 7-10. The error bars depict the unbiased standard deviation 
might be responsible for such a phenomenon. However, extensive researches will be required for elucidating the mechanism in the future.

\section{Effect of conductivity and electric charge on particle separation}

Figure $4 \mathrm{a}-\mathrm{f}$ shows the volume-based kaolin suspension particle size distribution of influent and effluent of Runs 1-3. Here, the conductivity in influent of Runs $1-3$ was 3,560 , and $550 \mu \mathrm{S} / \mathrm{cm}$, respectively (Table 2 ) and a terminal voltage of $+1.0 \mathrm{~V}$ was applied for Run 3 alone (Table 1). In addition, it is notable that the diameter of kaolin particles used in the experiments was in the range of 0.1-4.0 $\mu \mathrm{m}$. However, the kaolin particle diameter increased to the range of $0.139-8.200 \mu \mathrm{m}$ in the influent of Run 1 (Fig. 4a),
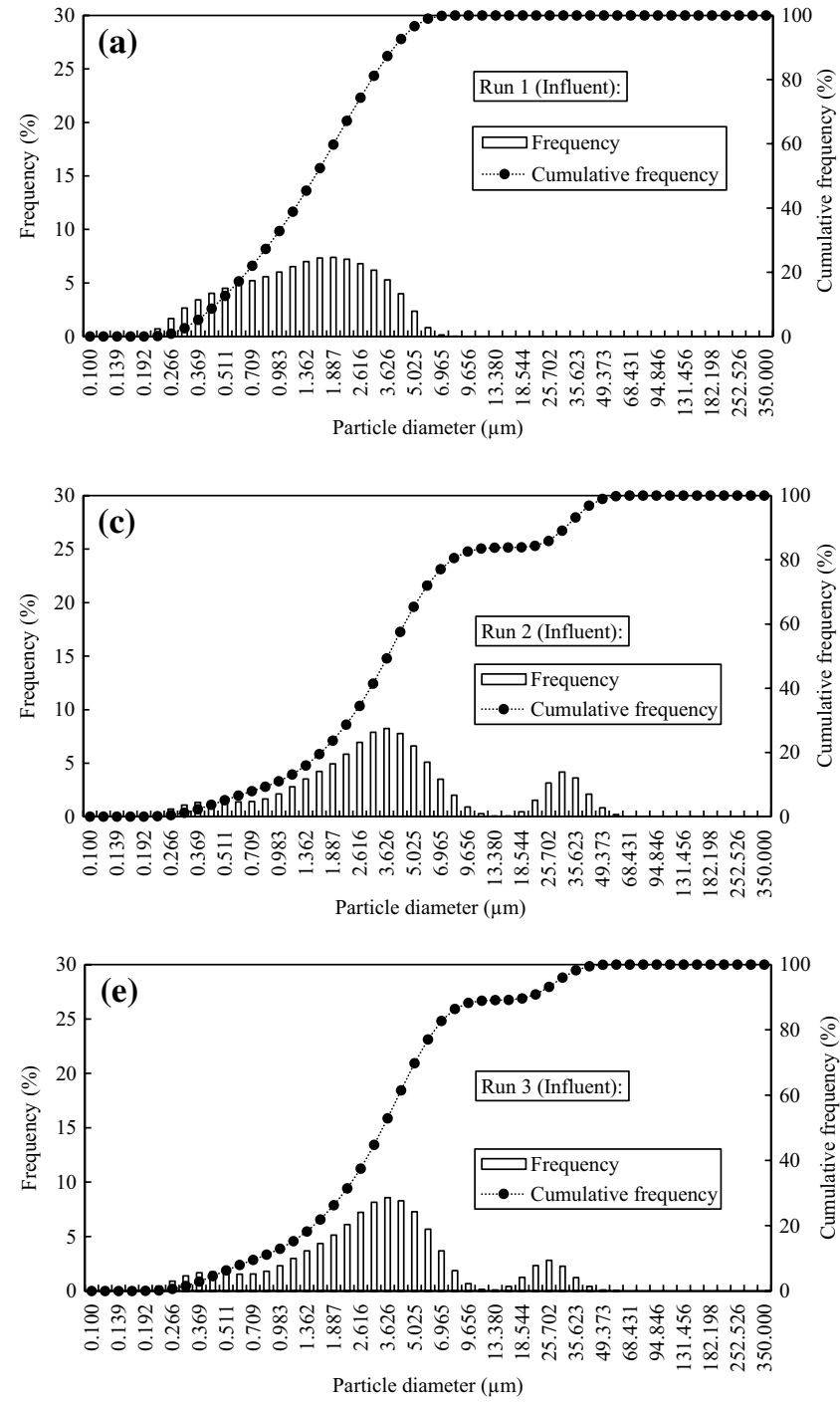

0.139-68.431 $\mu \mathrm{m}$ in the influent of Run 2 (Fig. 4c), and $0.139-58.126 \mu \mathrm{m}$ in the influent of Run 3 (Fig. 4e), because of self-flocculation.

Figure $4 b, d$ shows the particle size distribution of effluent in Runs 1 and 2. From these graphs, it is observed that the particles larger than $6.965 \mu \mathrm{m}$ were decreased by filtration without impressed voltage. This result indicates that the particles larger than $6.965 \mu \mathrm{m}$ were removed by the sieving mechanism and the adsorption mechanism by van der Waals forces.

Figure $4 \mathrm{f}$ shows the particles were completely removed by the depth filtration with the impressed voltage at $+1.0 \mathrm{~V}$. Accordingly, it was inferred that smaller particles less than $6.965 \mu \mathrm{m}$ were mainly removed by electrokinetic adsorption mechanism. On the other hand, smaller particles within the range of $0.100-0.266 \mu \mathrm{m}$ in the effluent of Run 1 (Fig. 4b)
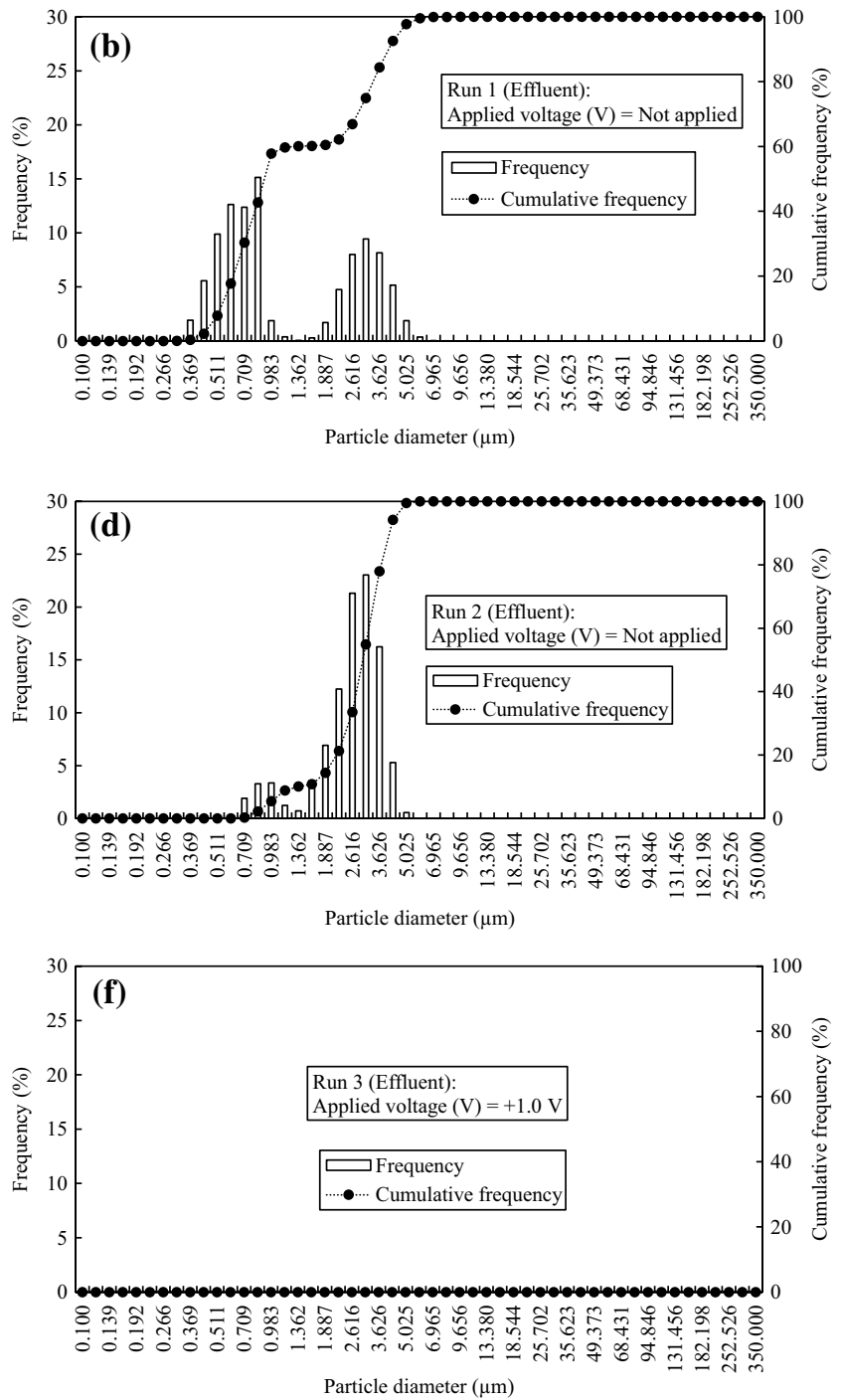

Fig. 4 a-f Volume-based kaolin suspension particle size distribution of influent and effluent of Runs 1-3, where as a solvent for kaolin particle, DW was used in Run 1 and DW with $5 \mathrm{mM} \mathrm{NaCl}$ was used in Runs 2-3 
and $0.100-0.434 \mu \mathrm{m}$ in the effluent of Run 2 (Fig. 4d) were found to be decreased without electric charge and thought to be due to the effect of self-aggregation of small particles during the filtration.

Figure 5 shows the SS, turbidity, and color removal efficiency of Runs 1-3. The influent of Run 1 with the EC of $3 \mu \mathrm{S} / \mathrm{cm}$ was filtrated without application of terminal voltage, and SS removal efficiency was found to be $92.2 \%$. But, when the influent of Run 2 with the EC of $560 \mu \mathrm{S} / \mathrm{cm}$ was filtrated without application of terminal voltage like Run 1, SS removal efficiency was found to be a little bit more than Run 1 , and it was found to be $97.3 \%$. Due to addition of $\mathrm{NaCl}$ in Run 2, the ionic strength of the solution was intensified and the thickness of the electrical double layer was decreased, which helped to enhance the particles contact with the filter media and affected in particle removal efficiency (Rica et al. 2012). Moreover, the application of terminal voltage $(+1.0 \mathrm{~V})$ in Run 3 showed $100 \%$ removal efficiency of all parameters (Fig. 5) probably due to the electrostatic attraction between the particles and the filter media (Lee et al. 2012). The overall rejection of particles in a filtration system depends on several factors such as the kaolin particle size distribution and filter media, namely filter media particle size, filter media material, filter bed length, etc. Here, the particle removal efficiency widely changed and is thought to be due to the influence of the filtration system used.

From the above discussions it can be concluded that the kaolin particles in size more than $6.965 \mu \mathrm{m}$ in diameter were physically clogged by the pore space of the filter module and physically adsorbed on the filter media by van der Waals forces, but the kaolin particles less than $6.965 \mu \mathrm{m}$ were mainly trapped by the electrostatic adsorption onto the filter media. Considering the $100 \%$ removal efficiency of all indices in Run 3, a terminal voltage of $+1.0 \mathrm{~V}$ was adopted at the following experiments (Runs 4-10) using synthetic contaminated source water, anionic surfactant, and Fe-contained water.

\section{Kaolin particle and iron removal performances in synthetic contaminated source water and anionic surfactant-contained water through filtration}

The SS, turbidity, color, and Fe removal performances were observed on Runs 4-10 at the terminal voltage of $+1.0 \mathrm{~V}$ with the filtration hydraulic loading of $283 \mathrm{~L} / \mathrm{m}^{2} / \mathrm{min}$ (Table 1). Since $\mathrm{Fe}^{2+}$ was spiked in the influent of Runs 7-10 at the concentration of $10 \mathrm{mg} / \mathrm{L}$, SS in the influent was found to be a little bit more than that of Runs 1-6 (Table 2). Figure $6 \mathrm{a}-\mathrm{n}$ shows the volume-based particle size distribution of influent and effluent of Runs 4-10. The particle size distribution of influent in Runs 4, 5, and 6 (Fig. 6a, c, e) shows the similar pattern to that in influent of Run 1 (Fig. 4a), though the influent in Runs 4, 5, and 6 had the similar EC of 480, 670 , and $770 \mu \mathrm{S} / \mathrm{cm}$ to that in Run $2(\mathrm{EC}=560 \mu \mathrm{S} / \mathrm{cm})$ and $3(\mathrm{EC}=550 \mu \mathrm{S} / \mathrm{cm})$. Figure 7 shows the SS, turbidity, color, and Fe removal efficiency of Runs 4-10. In the case of Runs 4-6, SS removal efficiency was found to be lower than that of other runs, where synthetic contaminated source water (Table 3) was used for the dilution of kaolin particles in Runs 4 and 5 and kaolin particles with sodium lauryl sulfate was diluted with DW in Run 6.

The SS removal efficiency was $22.2 \%$ in Run 4 at pH 6.7, $45.7 \%$ in Run 5 at pH 7.8, and 51.1\% in Run 6 at pH 6.6, respectively, though $100 \%$ removal efficiency was observed

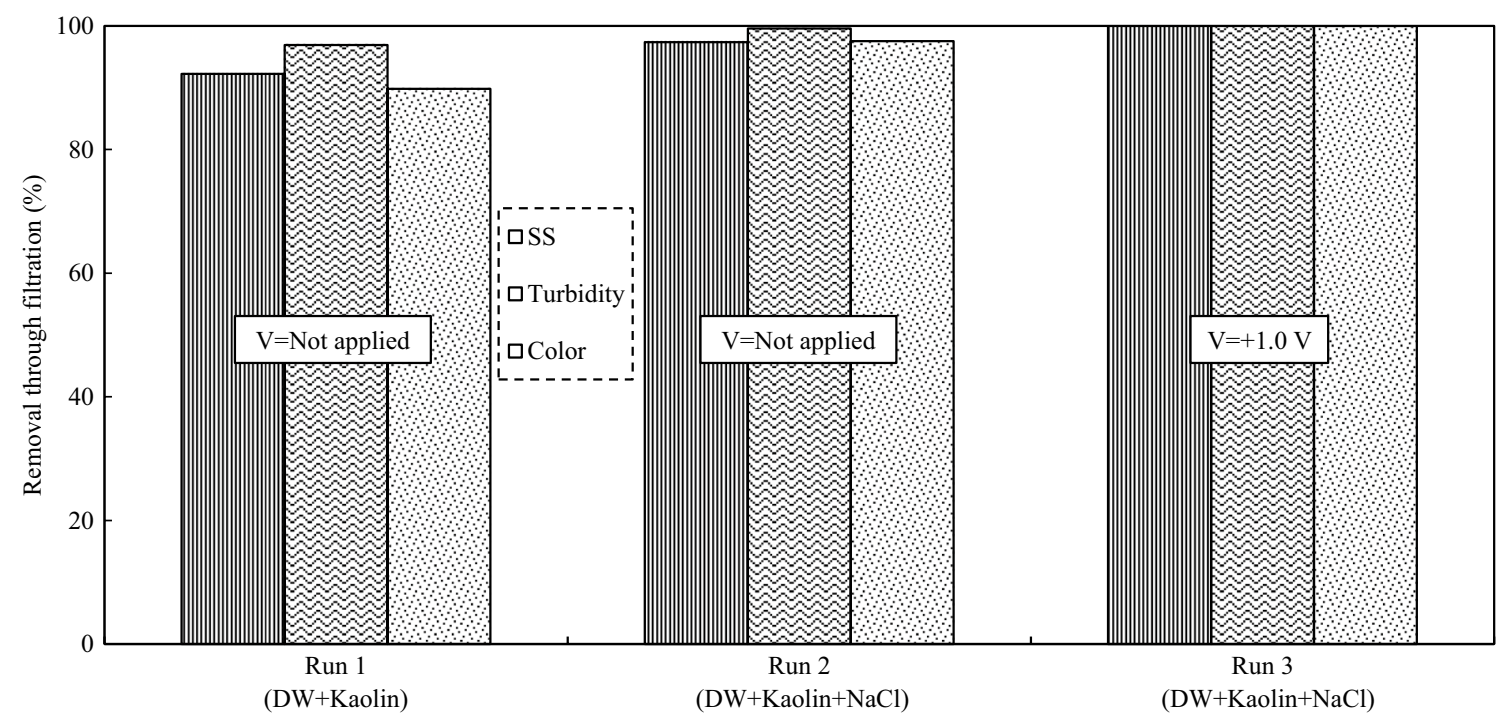

Fig. 5 SS, turbidity, and color removal efficiency of Runs $1-3$ at the filtration hydraulic loading of $283 \mathrm{~L} / \mathrm{m}^{2} / \mathrm{min}$, without application of terminal voltage in Runs 1 and 2, and $+1.0 \mathrm{~V}$ terminal voltage was applied in Run 3 

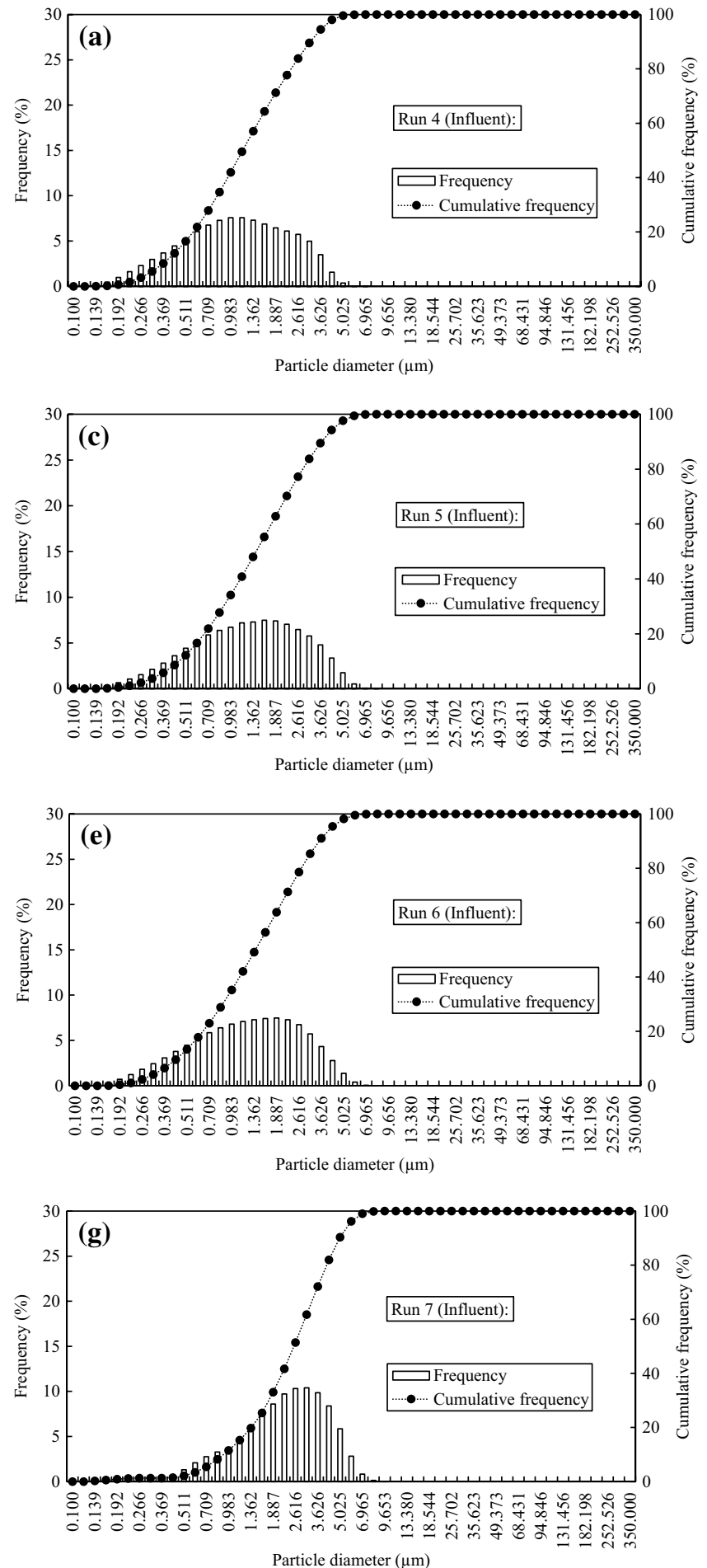

Fig. 6 a-n Volume-based kaolin suspension particle size distribution of influent and effluent of Runs 4-10, where synthetic contaminated source water (Table 2) was used as a solvent in Runs 4 and 5. Sodium

at Run 3. In Run 6, SS removal efficiency was found to be decreased due to the addition of sodium lauryl sulfate probably due to the adsorption of negatively charged sodium lauryl sulfate onto the filter media, which changed the surface charge
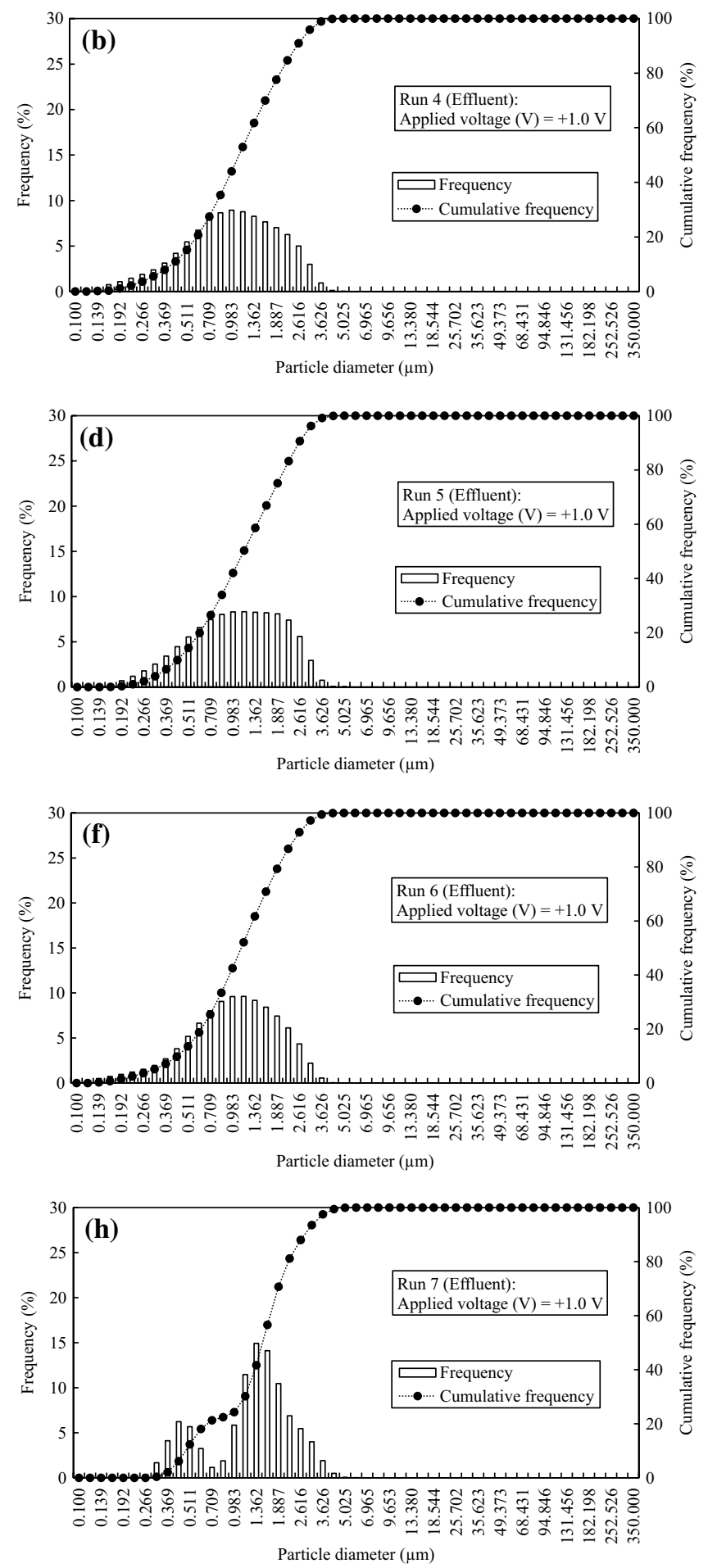

lauryl sulfate at the concentration of $100 \mathrm{mg} / \mathrm{L}$ was used in Runs 6, 9, and 10 , and Fe was spiked at the concentration of $10 \mathrm{mg} / \mathrm{L}$ in Runs $7-10$

of filter media from positive to negative. Besides, SS removal efficiency in Runs 4 and 5 was found to be much lower than in Run 6. Here, it is assumed that anionic surfactant-like compounds were contained in the wastewater, affected seriously in 

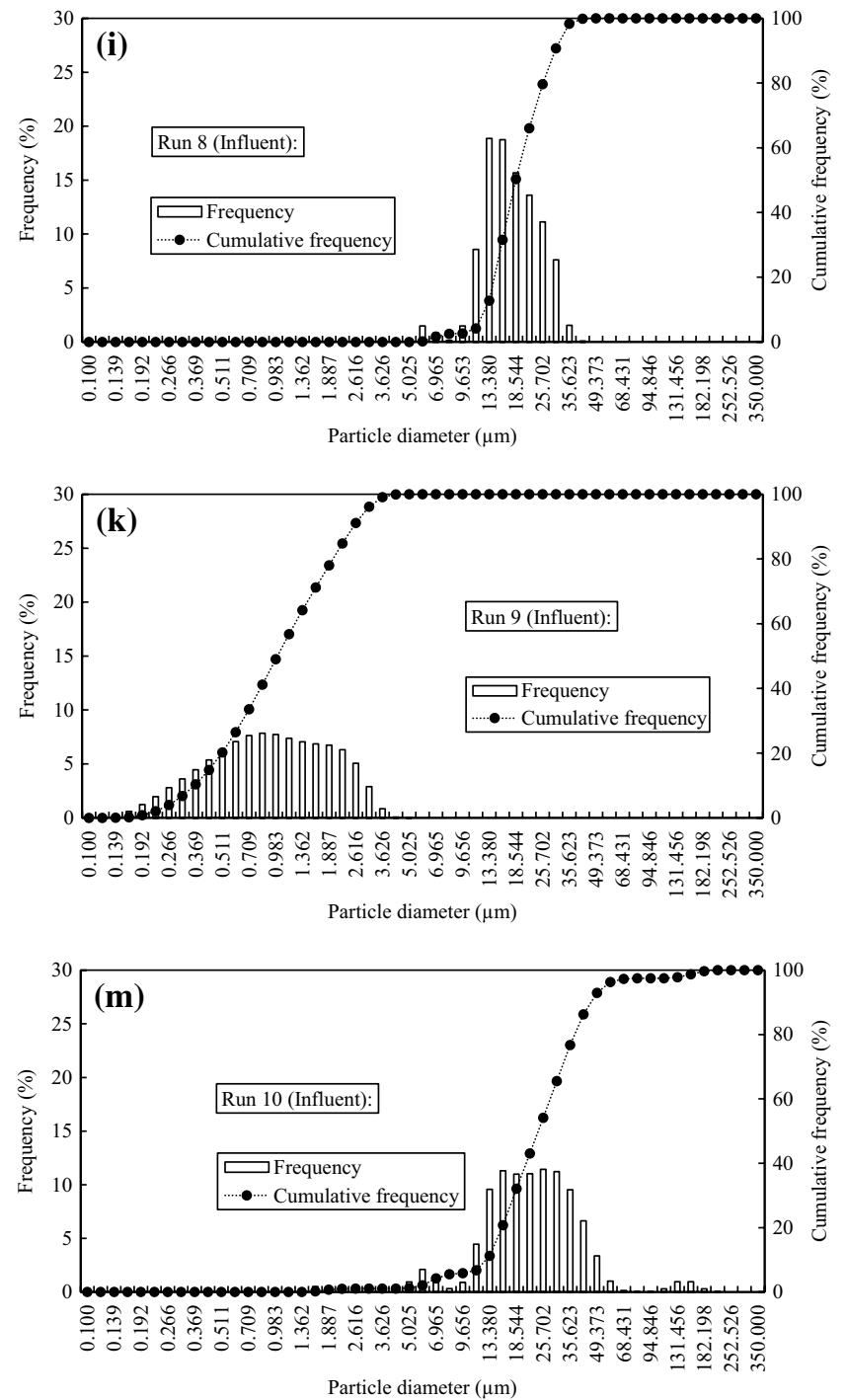

Fig. 6 (continued)

charge-based particle removal mechanism of the depth filtration system (Becerra et al. 2010; Gehrke et al. 2015).

Figure $6 \mathrm{~g}$, i shows the particle size distribution of Runs 7 and 8 in the influent of kaolin suspension with Fe. The particles in the influent were found to be in the range of $0.118-9.653 \mu \mathrm{m}$ in Run 7 and 4.268-41.938 $\mu \mathrm{m}$ in Run 8. Although Fe was spiked at the same concentration of $10 \mathrm{mg} / \mathrm{L}$ in Runs 7 and 8, the particle size distribution showed the different pattern. This was happened due to the difference in the oxidizing behavior of $\mathrm{Fe}$ at acidic and alkaline $\mathrm{pH}$. In the case of Run $8, \mathrm{Fe}$ was completely oxidized at $\mathrm{pH} 8.6$ as given in Eqs. 1 and 2 and the $\mathrm{Fe}(\mathrm{OH})_{3}$ flocs were accumulated in the solution, which formed larger particles in comparison with original kaolin particles.

$4 \mathrm{Fe}^{2+}+\mathrm{O}_{2}+4 \mathrm{H}^{+} \rightarrow 4 \mathrm{Fe}^{3+}+2 \mathrm{H}_{2} \mathrm{O}$
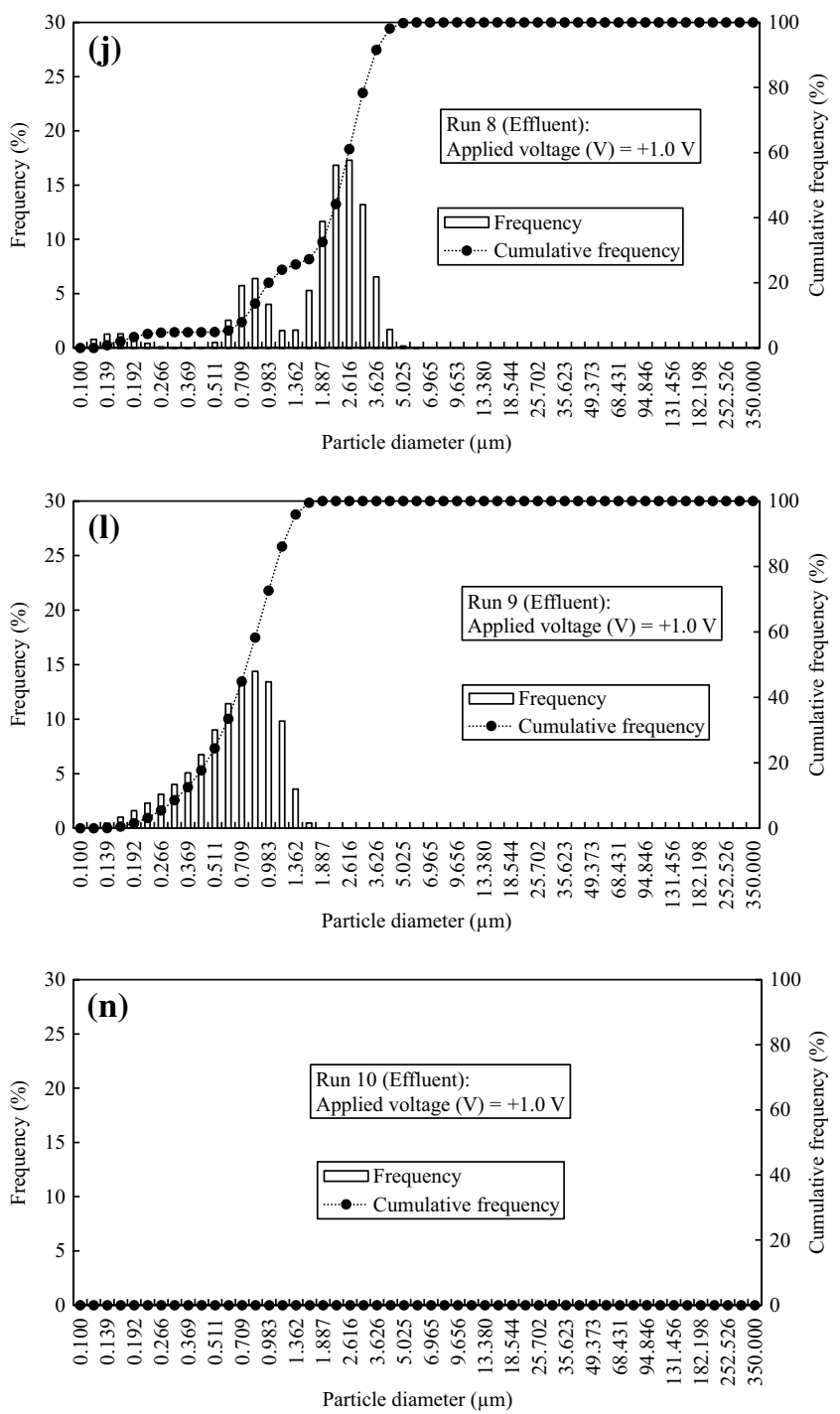

Particle diameter $(\mu \mathrm{m})$

$\mathrm{Fe}^{3+}+3 \mathrm{OH}^{-} \rightarrow \mathrm{Fe}(\mathrm{OH})_{3} \downarrow$

As a result, SS removal efficiency in Run 8 was nearly equal to $100 \%$ (Fig. 7). The Fe removal efficiency of $96.4 \%$ in Run 8 supported the above discussion. The less amount of Fe removal efficiency in Run 7 was thought to be due to the partial oxidation of $\mathrm{Fe}$ at acidic $\mathrm{pH}$ of 4.6, which is supported by the low Fe removal efficiency of $29.9 \%$ as shown in Fig. 7. The un-oxidized Fe easily passed through the filter module, because both the filter module and the $\mathrm{Fe}$ were positively charged.

Figure $6 \mathrm{k}, \mathrm{m}$ shows the particle size distribution of Runs 9 and 10 in the influent of kaolin suspension with sodium lauryl sulfate and Fe. Here, the particles were found within the range of $0.118-5.025 \mu \mathrm{m}$ in Run 9 and $0.983-214.498 \mu \mathrm{m}$ in Run 10. The influent particle size 


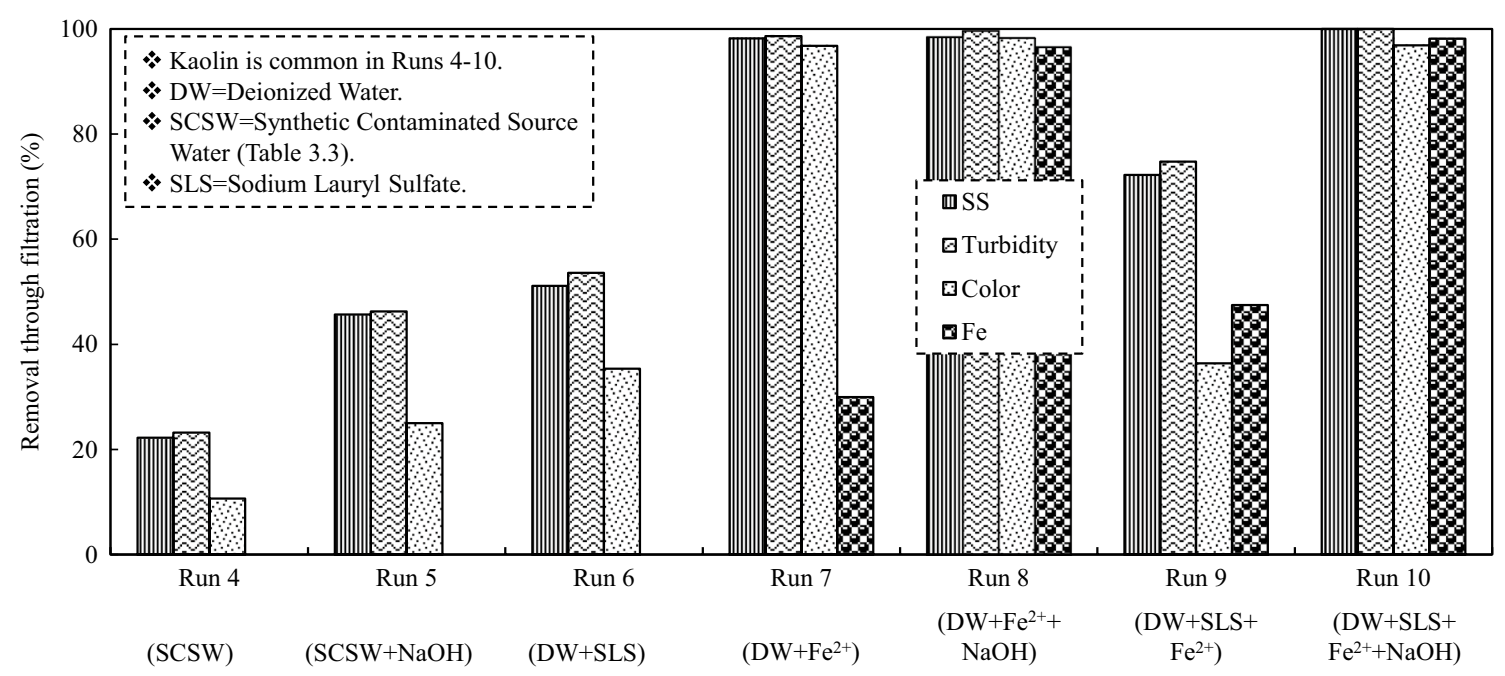

Fig. 7 SS, turbidity, color, and Fe removal efficiency of Runs $4-10$ at the filtration hydraulic loading of $283 \mathrm{~L} / \mathrm{m}^{2} / \mathrm{min}$, with the applied terminal voltage of $+1.0 \mathrm{~V}$

distribution of Runs 9 and 10 shows the similar pattern to that of Runs 7 and 8 . Moreover, the influent particle size distribution of Runs 6 and 9 was found in the same range like Run 1 (Fig. 4a), though sodium lauryl sulfate was added in Runs 6 and 9. This result suggests that sodium lauryl sulfate did not take part in particle aggregation. The SS removal efficiency in Run 9 was not so high $(72.2 \%)$ due to the presence of anionic surfactant as aforementioned in Run 6, and the removal efficiency of $\mathrm{Fe}$ was also low (47.5\%) due to the acidic $\mathrm{pH}$ as was mentioned in Run 7.

On the contrary to Run 9, the SS removal efficiency and the Fe removal efficiency in Run 10 were $100 \%$ and $98.1 \%$, respectively. Although sodium lauryl sulfate was present with the Fe colloids in the influent of Run 10, unlike Run 6 sodium lauryl sulfate could not influence on SS and Fe removal performances in Run 10 due to the stronger aggregation of kaolin suspension with Fe colloids at $\mathrm{pH}$ 7.9. Similar results were observed by Gupta et al. (2011).

From the above experimental results, it could be summarize that kaolin particle removal performances were significantly affected by the contaminated source water (Runs 4 and 5) as well as anionic surfactant-contained water (Run 6) regardless of $\mathrm{pH}$. The complete kaolin particle removal was observed in the pure water (Run 3 ) and pure water with $\mathrm{Fe}$ at alkaline $\mathrm{pH}$ (Run 10). Similarly, Fe removal performances were found to be affected in acidic $\mathrm{pH}$ (Runs 7 and 9) due to the partial oxidation, and 96.4\% Fe removal was observed in Run 8 and $98.1 \%$ was observed in Run 10 at slightly alkaline $\mathrm{pH}$.

\section{Evaluation of total coliform (TC) and general bacteria (GB) removal performances through filtration}

Figure 8 shows the total coliform (TC) and general bacteria (GB) removal performances. This experiment was conducted to observe the TC and GB removal performances through filtration at the hydraulic loading of $283 \mathrm{~L} / \mathrm{m}^{2} / \mathrm{min}$ with the terminal voltage of $+1.0 \mathrm{~V}$. To conduct this experiment, municipal wastewater of Ryukoku University was diluted by five times with normal tap water. Then, it was used as influent for the source of TC and GB. Here, the TC and GB concentration in the influent was found to be $88,800 \mathrm{CFU} /$ $\mathrm{mL}$ and 116,000 CFU/mL, respectively. The filtrated water

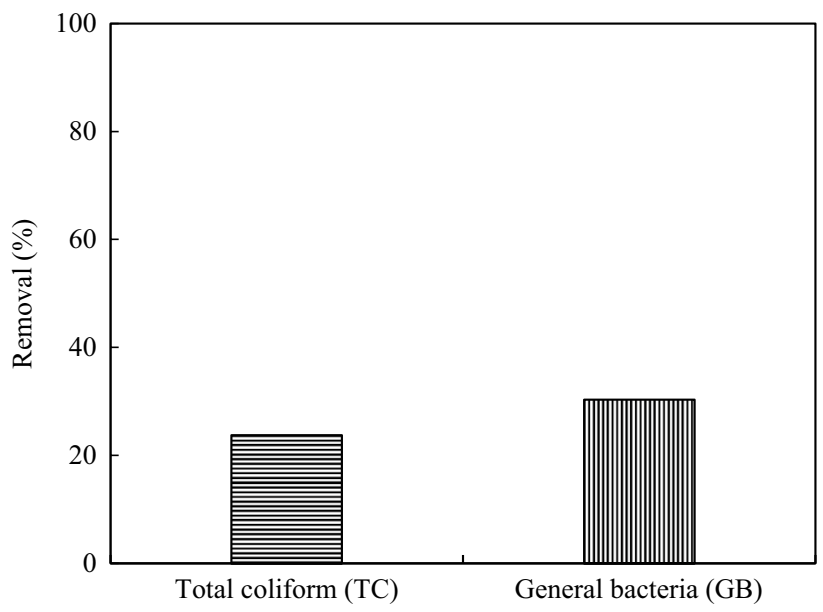

Fig. 8 TC and GB removal performances through filtration with the terminal voltage of $+1.0 \mathrm{~V}$ and at the filtration hydraulic loading of $283 \mathrm{~L} / \mathrm{m}^{2} / \mathrm{min}$ 

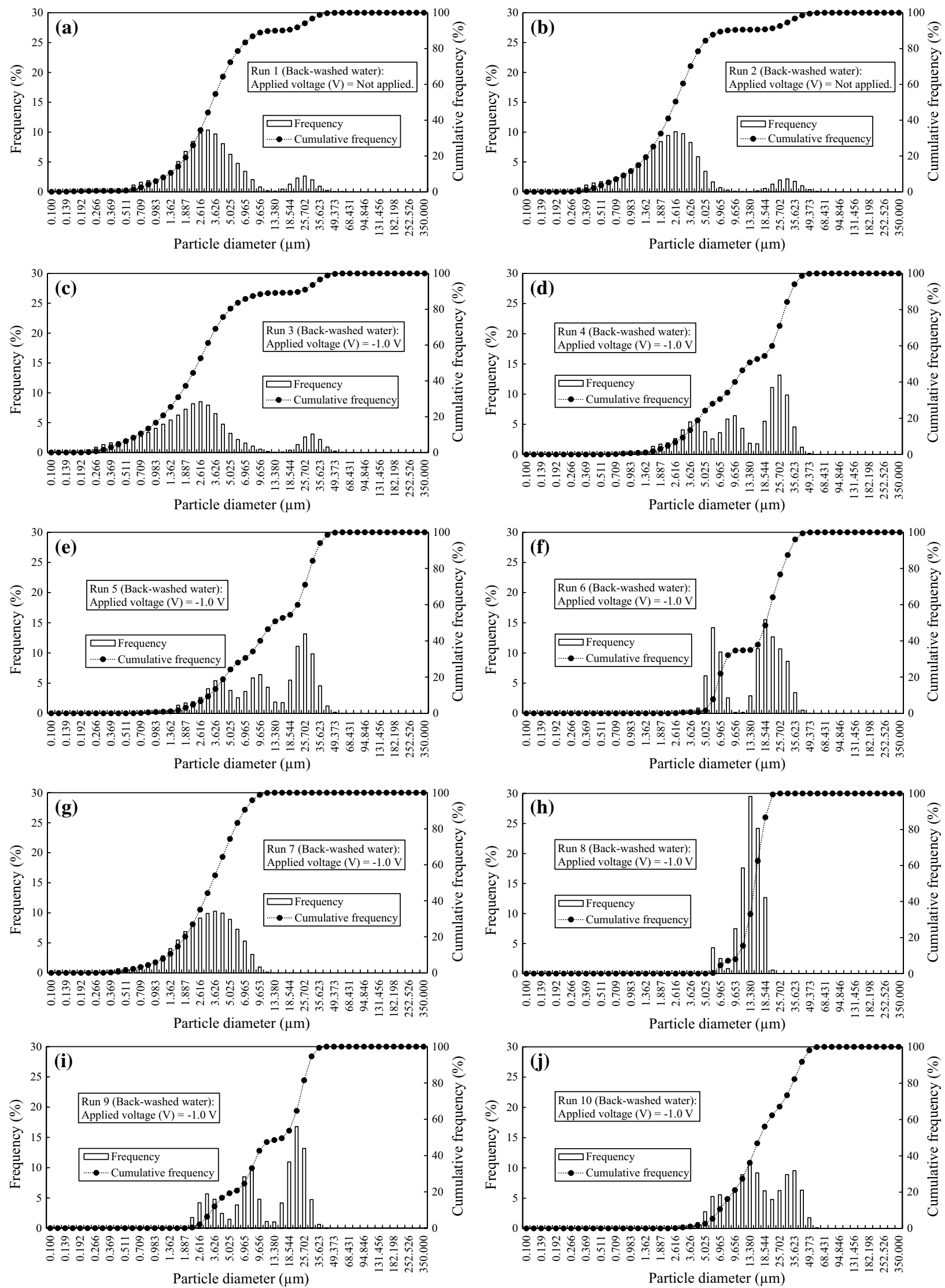
४Fig. 9 a-j Volume-based kaolin suspension particle size distribution in back-washed water of Runs 1-10, where the particles in Runs 1-6 were mainly kaolin and Runs 7-10 were kaolin with Fe colloids

volume was $2000 \mathrm{~mL}$. In this experimental study, the TC and GB removal efficiency through filtration was found to be $23.7 \%$ and $30.3 \%$, respectively. Similar removal efficiencies were observed by Michen et al. (2012) and Jenkins et al. (2011).

\section{Effect of back-washing on Kaolin particle and iron washout from filter media}

A series of back-washing experiments were demonstrated on Runs 1-10 at the back-washing hydraulic loading of $1274 \mathrm{~L} /$ $\mathrm{m}^{2} / \mathrm{min}$, using a back-washing solution of DW for Runs $1-2$ and $5 \mathrm{mM} \mathrm{NaCl}$ solution $(\mathrm{EC}=580 \mu \mathrm{S} / \mathrm{cm})$ for Runs 3-10. At the back-washing mode, $-1.0 \mathrm{~V}$ potential was applied at Runs 3-10 and the potential was not applied at Runs 1-2 (Fig. 2). Figure 9a-j shows the volume-based particle size distribution in back-washed water of Runs 1-10. As a whole, the particles diameter of the back-washed water in Runs 1-10 was found to be in the range of 0.139-68.431 $\mu \mathrm{m}$. Here, part of particles in back-washed water of all the runs was found to be aggregated. The particle aggregation in back-washed water may occur through aeroflocs mechanism due to air intrusion while shifting the operation mode from filtration to the back-washing (Oliveira et al. 2014).

Figure 10 shows the SS, turbidity, color, and Fe washout removal performances of Runs 1-10. Here, the washout removal efficiency is defined as the ratio of the amount of particles washed away by the back-washing to the amount of particles removed at the filtration step. The SS washout removal efficiency in Run 3 was higher $(72.5 \%)$ than that in Run $1(60.0 \%)$ and slightly higher than that in Run 2 $(68.2 \%)$.

The higher washout removal efficiency in Run 3 was achieved for the application of terminal voltage of $-1.0 \mathrm{~V}$, which generated a repulsive fore against the kaolin particles and facilitated in washout removal process. Similar result was observed by Min et al. (2013) which supports this discussion.

Among Runs 1-10, SS washout removal efficiency in Runs 6, 9, and 10 remained low, namely $7.8 \%, 4.6 \%$, and $12.5 \%$, respectively (Fig. 10). Since sodium lauryl sulfate was added into the influent of Runs 6,9, and 10, it is inferred to inhibit the repulsive force mechanism through the linkage between the filter medium and particles by the hydrophobic tails in the surfactant.

In the case of Runs 4 and 5, sodium lauryl sulfate was not added in the influent, but kaolin particle was diluted in the wastewater given in Table 3. Here, the SS washout removal efficiency was found to be relatively low, namely $59.5 \%$ in
Run 4 and 55.0\% in Run 5. In these cases, such a low washout removal efficiency is predicted due to the presence of anionic surfactant-like compounds in the wastewater, which affected in repulsion mechanism.

The SS washout removal efficiency in Runs 7 (45.9\%) and $8(50.7 \%)$ was found to be lower than that in Run 3 (72.5\%), but to be higher than that in Runs 6, 9, and 10. In Runs 7 and $8, \mathrm{Fe}$ was spiked into the influent without addition of sodium lauryl sulfate. As a result, SS washout removal was not so much hindered by Fe like Runs 6, 9, and 10. However, SS washout removal efficiency in Run 7 was found to be a little bit less than in Run 8. In this case, the un-oxidized $\mathrm{Fe}^{2+}$ was positively charged at $\mathrm{pH}$ 4.6. As a result, the application of negative potential in the back-washing step created an attracting force between the $\mathrm{Fe}^{2+}$ and the filter media instead of repulsive force, which hindered in SS washout removal efficiency in Run 7.

The Fe washout removal efficiency was measured in Runs 7-10. The Fe washout removal efficiency in Run 8 (59.7\%) was to some extent higher than that in Run 7 (49.6\%). Fe was completely oxidized at alkaline $\mathrm{pH}$ and formed hydroxide flocs in Run 8. As a result, a thin soft cake layer of $\mathrm{Fe}(\mathrm{OH})_{3}$ would be formed on the surface of filter media, which were washed away easily at the high back-washing hydraulic loading of $1274 \mathrm{~L} / \mathrm{m}^{2} / \mathrm{min}$ from the surface of filter media during the back-washing stage. But, in the case of Runs 9 (6.4\%) and 10 $(15.1 \%)$ the Fe washout removal efficiencies were found to be comparatively very low with respect to Run 8 (59.7\%). Since sodium lauryl sulfate was present in the influent of Runs 9 and 10, which influenced $\mathrm{Fe}$ washout removal performances in the back-washing step. This can be explained in such a way that the positively charged hydrophobic tails of sodium lauryl sulfate covered the oxidized or un-oxidized Fe and the application of negative potential in the back-washing step created an attracting force that captured the $\mathrm{Fe}$ and hindered in washout removal performances.

From the above discussions, it can be summarized that simple back-washing has the potentiality for the washout of physically clogged particles if the particles are deposited over the surface of the filter media like a cake layer. The washout removal efficiency by back-washing of the particles can be enhanced if a repulsive force is created between the particles and the filter media. On the other hand, the washout removal efficiency can be decreased dramatically if the particles are in contact with the anionic surfactant or anionic surfactantlike compounds, because these types of surfactants inhibit in repulsive force mechanism between the particles and the filter media. 


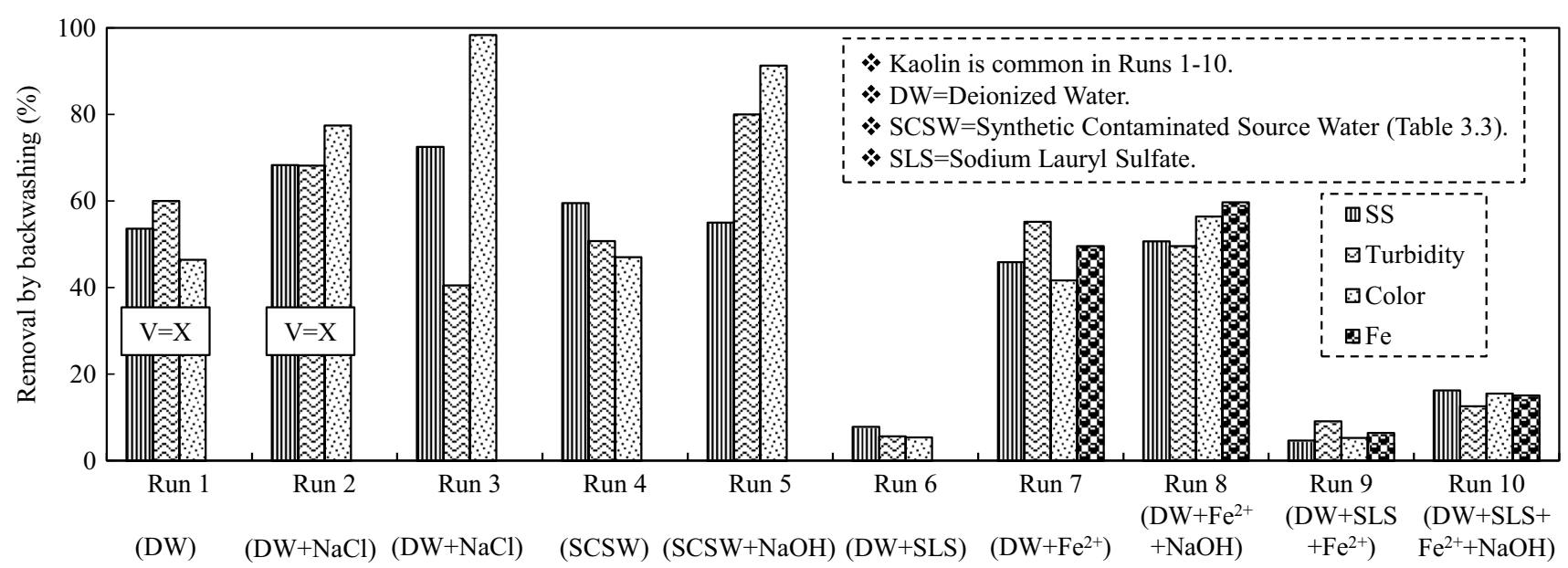

Fig. 10 SS, turbidity, color, and Fe washout removal performances of Runs 1-10 by back-washing at the back-washing hydraulic loading of $1274 \mathrm{~L} / \mathrm{m}^{2} / \mathrm{min}$, where terminal voltage was not applied in Runs 1 and 2 and $-1.0 \mathrm{~V}$ terminal voltage was applied in Runs 3-10

\section{Conclusion}

In this study, an effect of active control potential on filter medium was demonstrated at the terminal voltage of $+1.0 \mathrm{~V}$ at the filtration operation and of $-1.0 \mathrm{~V}$ at the back-washing operation using kaolin particle suspensions. An electric current was not observed, when the terminal voltage was impressed, because the applied terminal voltage of $\pm 1.0 \mathrm{~V}$ was within the potential window of water electrolysis. Accordingly, the electricity was used only for charging the electrical double layers of filter media and counter electrode. This symptom denotes the zero energy consumption technique, and this operation could be highly effective in enhancing charge-based particle separation mechanism in depth filtration.

The zeta potential of kaolin suspension in pure water and synthetic contaminated source water with or without an anionic surfactant showed the negative values, but it varied in a wide range depending on the $\mathrm{pH}$ of the solution and iron contamination. The kaolin particle removal efficiency in filtration was observed $100 \%$ at the terminal voltage of $+1.0 \mathrm{~V}$ in the kaolin suspension in $5 \mathrm{mM}$ sodium chloride solution at the hydraulic loading of $283 \mathrm{~L} / \mathrm{m}^{2} / \mathrm{min}$. However, the kaolin particle removal efficiency decreased to $22.2-45.7 \%$ in synthetic contaminated source water and $51.1 \%$ in anionic surfactant-contained water. On the contrary, the kaolin particle washout removal efficiency was observed $72.5 \%$ at the terminal voltage of $-1.0 \mathrm{~V}$ at the back-washing hydraulic loading of $1274 \mathrm{~L} / \mathrm{m}^{2} / \mathrm{min}$. But, the kaolin particle washout removal efficiency was decreased to $55.0-59.5 \%$ in wastewater and $4.6-12.5 \%$ in anionic surfactant-contaminated water. The iron colloids suspension washout removal performances were observed to be $59.7 \%$ in anionic surfactant-free water, but $6.4 \%$ in anionic surfactant-contained water.
Moreover, total coliform and general bacteria removal efficiency was found to be $23.7 \%$ and $30.3 \%$, respectively. Therefore, the application of electric charge technique in the depth filtration would be effective in removing colloidal size particles like inorganic and organic particles in the sewagecontaminated water, though the removal of total coliform and general bacteria was not expected very much. From this experimental study, I recommend $0.283 \mathrm{~m}^{3} / \mathrm{m}^{2} / \mathrm{min}$ hydraulic loading for the removal of organic aggregates and iron colloids with the terminal voltage of $+1.0 \mathrm{~V}$. For the washout of organic aggregates and iron colloids from the filter media, I recommend the hydraulic loading of $1.27 \mathrm{~m}^{3} / \mathrm{m}^{2} /$ min with $5 \mathrm{mM}$ sodium chloride-contained pure water with the terminal voltage of $-1.0 \mathrm{~V}$.

Open Access This article is distributed under the terms of the Creative Commons Attribution 4.0 International License (http://creativeco mmons.org/licenses/by/4.0/), which permits unrestricted use, distribution, and reproduction in any medium, provided you give appropriate credit to the original author(s) and the source, provide a link to the Creative Commons license, and indicate if changes were made.

\section{References}

Aiken GR, Hsu-Kim H, Ryan JN (2011) Influence of dissolved organic matter on the environmental fate of metals, nanoparticles, and colloids. Environ Sci Technol 45(8):3196-3201

Aksoy YY, Kaya A (2011) A study of factors affecting on the zeta potential of kaolinite and quartz powder. Environ Earth Sci 62(4):697-705

Becerra FY, Acosta EJ, Allen DG (2010) Alkaline extraction of wastewater activated sludge biosolids. Bioresour Technol 101(18):6972-6980 
Bedrikovetsky P, Siqueira FD, Furtado CA, Souza ALS (2011) Modified particle detachment model for colloidal transport in porous media. Transp Porous Media 86(2):353-383

Coustumer SL, Fletcher TD, Deletic A, Barraud S, Poelsma P (2012) The influence of design parameters on clogging of stormwater biofilters: a large-scale column study. Water Res 46(20):6743-6752

Ding B, Li C, Dong X (2015) Percolation-based model for strainingdominant deep bed filtration. Separ Purif Technol 147:82-89

Gehrke I, Geiser A, Somborn-Schulz A (2015) Innovations in nanotechnology for water treatment. Nanotechnol Sci Appl 8:1-17

Ghernaout D, Ghernaout B (2012) Sweep flocculation as a second form of charge neutralization-a review. Desalin Water Treat 44(1-3):15-28

Gupta V, Hampton MA, Stokes JR, Nguyen AV, Miller JD (2011) Particle interactions in kaolinite suspensions and corresponding aggregate structures. J Colloid Interface Sci 359(1):95-103

Jenkins MW, Tiwari SK, Darby J (2011) Bacterial, viral and turbidity removal by intermittent slow sand filtration for household use in developing countries: experimental investigation and modeling. Water Res 45(18):6227-6239

Karan S, Wang Q, Samitsu S, Fujii Y, Ichinose I (2013) Ultrathin freestanding membranes from metal hydroxide nanostrands. J Membr Sci 448:270-291

Keller AA, Wang H, Zhou D, Lenihan HS, Cherr G, Cardinale BJ, Miller R, Ji Z (2010) Stability and aggregation of metal oxide nanoparticles in natural aqueous matrices. Environ Sci Technol 44(6):1962-1967

Kishimoto N, Kawasaki H, Sasaki T, Sasaki S (2010) Effect of active control of electric potential of filter medium on depth filtration. Water Sci Technol 62(5):1022-1027

Lee S, Laldawngliana C, Tiwari D (2012) Iron oxide nano-particlesimmobilized-sand material in the treatment of $\mathrm{Cu}(\mathrm{II}), \mathrm{Cd}(\mathrm{II})$ and $\mathrm{Pb}$ (II) contaminated waste waters. Chem Eng J 195-196:103-111

Leroy P, Tournassat C, Bizi M (2011) Influence of surface conductivity on the apparent zeta potential of $\mathrm{TiO}_{2}$ nanoparticles. J Colloid Interface Sci 356(2):442-453

Li Z, Deng S, Yu G, Huang J, Lim VC (2010) As(V) and As(III) removal from water by a $\mathrm{Ce}-\mathrm{Ti}$ oxide adsorbent: behavior and mechanism. Chem Eng J 161(1-2):106-113

Loderer C, Wörle A, Fuchs W (2012) Influence of different mesh filter module configurations on effluent quality and long-term filtration performance. Environ Sci Technol 46(7):3144-3850

Loo S, Fane AG, Krantz FW, Lim T (2012) Emergency water supply: a review of potential technologies and selection criteria. Water Res 46(10):3125-3151
Mahmoud A, Olivier J, Vaxelaire J, Hoadley AFA (2010) Electrical field: a historical review of its application and contributions in wastewater sludge dewatering. Water Res 44(8):2381-2407

Michen B, Meder F, Rust A, Fritsch J, Aneziris C, Graule T (2012) Virus removal in ceramic depth filters based on diatomaceous earth. Water Sci Technol 46(2):1170-1177

Min F, Zhao Q, Liu L (2013) Experimental study on electrokinetic of kaolinite particles in aqueous suspensions. Physicochem Probl Miner Process 49(2):659-672

Moayedi H, Huat BBK, Kazemian S, Daneshmand S, Moazami D, Niroumand H (2011) Electrophoresis of suspended kaolinite in multivalent electrolyte solution. Int J Electrochem Sci 6:6514-6524

Oliveira C, Rodrigues RT, Rubio J (2014) Operating parameters affecting the formation of kaolin aerated flocs in water and wastewater treatment. Clean-Soil Air Water 42(7):909-916

Rica RA, Brogioli D, Ziano R, Salerno D, Mantegazza F (2012) Ions transport and adsorption mechanisms in porous electrodes during capacitive-mixing double layer expansion (CDLE). J Phys Chem 116(32):16934-16938

Rice EW, Baird RB, Eaton AD, Clesceri LS (2012) Standard methods for the examination of water and wastewater, 22nd edn. American Public Health Association, American Water Works Association, Water Environment Federation, Washington, DC

Sun Y, Gao B, Bradford SA, Wu L, Chen H, Shi X, Wu J (2015) Transport, retention, and size perturbation of graphene oxide in saturated porous media: effects of input concentration and grain size. Water Res 64:24-33

Torkzaban S, Kim HN, Jiri Simunek J, Bradford SA (2010) Hysteresis of colloid retention and release in saturated porous media during transients in solution chemistry. Environ Sci Technol 44(5):1062-1669

Wang Y, Kim J, Baek J, Miller GW, Pennell KD (2012) Transport behavior of functionalized multi-wall carbon nanotubes in watersaturated quartz sand as a function of tube length. Water Res 46(14):4521-4531

Publisher's Note Springer Nature remains neutral with regard to jurisdictional claims in published maps and institutional affiliations. 